\title{
The relationship between the feedback environment and creativity: a self-motives perspective
}

This article was published in the following Dove Press journal: Psychology Research and Behavior Management

\author{
Zhenxing Gong' \\ Chao Shan' \\ Haizhen $\mathrm{Yu}^{2}$ \\ 'Department of Business Administration, \\ School of Business, Liaocheng University, \\ Liaocheng 252000, People's Republic of \\ China; ${ }^{2}$ Technical Reconnaissance \\ Department, Liaocheng Public Security \\ Bureau, Liaocheng 252000, People's \\ Republic of China
}

Background: For companies, employee creativity is vital to gaining competitive business advantages. Research regarding creativity has focused on contextual factors such as feedback, but results of studies on the relationship between feedback and creativity are inconsistent; further, only a handful of studies have been carried out from the perspective of coworkers. In this study, we aimed to analyze the association between the coworker feedback environment and creativity, to test the mediating role of feedback monitoring in this relationship and to test the moderating role of self-motivation among employees in China.

Methods: A coworker feedback environment survey, a coworker feedback monitoring questionnaire, a self-motivation scale and a creativity scale were used. The staff submitted 264 questionnaires, of which $235(74.6 \%)$ were completed by the participants. Among the respondents in the sample, $132(56.2 \%)$ were men, and $103(43.8 \%)$ were women. The mean age is 30 and age range from 24-49. Mplus 7.11 software was used to perform descriptive analysis, Spearman's correlation analysis, mediating analysis and moderation analysis.

Results: Coworker feedback environment was positively associated with creativity $(\beta=0.60$, $p<0.01$ ) after controlling for the demographic variable. Coworker feedback monitoring partially mediated the relationship between coworker feedback environment and creativity $(\chi 2 / d f=2.5, \mathrm{RMSEA}=0.05 ; \mathrm{CFI}=0.93 ; \mathrm{GFI}=0.93)$. When self-assessment motivation is lower, the positive relationship between coworker feedback monitoring and creativity becomes stronger $(\beta=0.19)$; the same relationship becomes weaker $(\beta=0.01)$ when self-assessment motivation is higher.

Conclusion: It was suggested that a coworker feedback environment could improve employee creativity by promoting coworker feedback monitoring; creativity could be improved especially among employees who have lower self-assessment motivation.

Keywords: feedback environment, creativity, feedback seeking, self-motivation

\section{Introduction}

Creativity refers to novel and viable products, processes, or methods that are valuable to organizations. ${ }^{1}$ For companies, employee creativity is vital to gaining a competitive advantage. ${ }^{2}$ For years, research regarding the antecedents of employee creativity has focused on organizational environmental factors, such as work complexity, leadership styles, rewards, time constraints, and feedback. ${ }^{2,3}$ Although previous literature found that feedback can improve creativity, a meta-analysis indicated that more than $38 \%$ of the feedback has a negative effect on creativity. ${ }^{4}$ It is essential to identify how to use feedback to improve creativity.
Correspondence: Zhenxing Gong

Department of Business Administration, School of Business, Liaocheng University, No. I Hunan Road, Dongchangfu District, Liaocheng 252000, People's Republic of China

Tel +86I8906350166

Email zxgongl18@I63.com 
Previous research on feedback and creativity compared and contrasted the effects of different types of feedback; however, this approach ignores the complexity of the feedback process. ${ }^{5}$ In this process, factors, such as the credibility of the feedback source, the feedback delivery, and the encouragement of feedback seeking, impact the feedback effect in a contextual sense. ${ }^{6}$ To fully understand the association between feedback and creativity, researchers have introduced the concept of a feedback environment, which refers to the contextual processes between a supervisor and his/her subordinates or coworkers, and this environment would exist in the coworkers' daily work environment rather than in a formal performance appraisal feedback session. ${ }^{5}$ Prior work has yet to deeply explore the consequences of the supervisor feedback environment; ${ }^{7}$ however, only a handful of studies have been carried out from the perspective of coworkers. This omission is consequential. Because coworkers are more approachable and are professionally equal relative to than their supervisors, there are more opportunities to exchange feedback with coworkers in daily life. ${ }^{8}$ Although existing research show that some dimensions of the coworker feedback environment, such as feedback validity and feedback seeking supporting, can influence creativity, ${ }^{9}$ little research has been performed on the impact of the coworker feedback environment on creativity.

As for the influence of the feedback environment on creativity, current research focuses on the internal psychological mechanism but neglects the role of feedback seeking. ${ }^{10}$ It still remains unclear how the coworker feedback environment actually influences creativity. ${ }^{11}$ Sedikides and Strube's self-motives theory deals with how individual receive, select, process, seek, and react to feedback, also focuses on the use of motivation to influence how individuals perform self-evaluations and seek information. ${ }^{12}$ In this paper, we believe that self-motives theory is of great importance for gaining a deep understanding the impact of feedback environment on creative performance.

As a proactive behavior, feedback seeking is the behavior of individuals who involves actively seeking valuable information in the organization so that it can be adapted to the organization's and individuals' development requirement. ${ }^{13}$ A supportive coworker feedback environment encourages coworkers to seek feedback, ${ }^{14}$ thereby enabling employees to improve their creativity. ${ }^{10}$ Employees are capable of seeking feedback by using feedback inquiry and feedback monitoring. According to self-motives theory, feedback often includes unfavorable information and might hurt selfesteem. Thus feedback seeking can be divided into feedback inquiry and feedback monitoring, but employees can emulate creative role models without losing the respect of their coworkers by using feedback monitoring. ${ }^{15}$ Feedback monitoring involves examining one's environment for indirect feedback cues. Employees observe the task progress of their coworkers to gain insights into aspects of their own performance. ${ }^{15}$ Especially in China, where maintaining the respect of others is a high cultural value, employees are more likely to adopt feedback monitoring from coworkers. ${ }^{1}$ However, the role of feedback monitoring in the relationship between coworker feedback environment and creativity is not clear because of the lack of empirical research. ${ }^{16}$

Unfortunately, a meta-analysis of feedback seeking showed that feedback seeking and creativity were not significantly positively related. ${ }^{17}$ Coworker feedback monitoring had a positive impact on creativity only under certain conditions. ${ }^{18}$ Self-motives theory classifies the motivations that drive people to perform evaluations and seek feedback into four categories: self-verification, selfenhancement, self-assessment, and self-improvement. ${ }^{19}$ Self-verification refers to strengthening individuals' feelings of prediction and control, thereby helping them to form a stable self-concept, and encouraging others to have the same views that the individuals have of themselves; self-enhancement is aimed at improving one's self-image and implementing self-protection due to assumed negative information; self-improvement is aimed at improving individuals' knowledge, abilities, and skills; and individuals who are driven by self-assessment motivation prefer external feedback, since they are interested in knowing the external environment's view of their appearance, abilities, and traits. ${ }^{12}$ Individuals who seek feedback by self-verification, self-enhancement and self-assessment motivations do not care about the accuracy of feedback, so these three motivations belong to the tactical aspect of self-concept enhancement and may weaken the impact of feedbackseeking behavior, but self-improvement motivation may not. ${ }^{20}$ Self-motivation reflects feedback-seeking motivation more comprehensively and solves the past lack of classification regarding feedback-seeking motivations; however, the moderating role of self-motivation in the relationship between feedback monitoring and creativity, especially in the Chinese culture, has not been fully clarified. ${ }^{21}$ 


\section{Coworker feedback environment and creativity}

The coworker feedback environment reflects the complexity of feedback, and it simultaneously highlights the feedback recipients' perception of feedback effectiveness and focuses on encouraging feedback-seeking behavior. ${ }^{22}$ Specifically, a supportive coworker feedback environment occurs when an employee believes that the coworker is credible, gives high-quality feedback, delivers feedback clearly, delivers both positive and negative feedback accurately, is accessible, and actively promotes feedback-seeking behavior. ${ }^{11}$ Most work has adopted a variable-centered approach, which calls for assessing how a composite score of seven feedback environment facets relates to outcomes. ${ }^{23}$ The reasons that the coworker feedback environment can affect creativity are as follows:

First, current research shows that some dimensions can influence creativity. For example, a feedback environment can provide the staff with clear feedback, wherein the purpose and function of the feedback are evident, thereby enhancing the creativity of the employees. Regarding feedback validity, the feedback process can act as an information source for employees to improve their work and learning performance. ${ }^{24}$ If coworkers support feedbackseeking behavior, they can provide themselves with the information required to promote the development of creative ideas. ${ }^{9}$

Second, a supportive environment provides reliable, accurate, and useful feedback information; delivers the information properly; and encourages employee feedback-seeking behavior. ${ }^{25}$ Such a feedback environment enables employees to clarify their self-performance standards based on organizational requirements, thereby reducing uncertainty and ambiguity. ${ }^{25}$ Additionally, the key to the creativity of employees is support. Both experimental and investigatory studies have consistently found that support enhances the work environment and is related to creativity. ${ }^{9}$ Therefore, we hypothesize the following:

Hypothesis 1: Coworker feedback environment positively impacts creativity

\section{The mediating role of coworker feedback monitoring}

A feedback environment has a multidimensional structure: a feedback environment can not only provide employees with support from supervisors and coworkers and offer credible and accurate feedback information appropriately but also encourage coworker feedback-seeking behavior, ${ }^{14}$ thereby enabling employees to improve their creativity. Feedback-seeking behaviors clarify the roles and goals of individuals to improve performance based on relevant information provided by a feedback environment. ${ }^{26} \mathrm{~A}$ feedback environment influences work behaviors, is related to high performance and rewards, and can encourage employees by providing them with expected working achievements. $^{27}$

Unlike traditional feedback, feedback-seeking theory argues that feedback receivers are able to self-regulate and should be proactive in their approach. Self-regulation theory states that individuals can plan their way forward through their own efforts and ultimately achieve their goals. ${ }^{20}$ Individual creativity may be influenced by one's social environment in the development process, but encouragement by coworkers can promote individual creativity as well. ${ }^{28}$ Previous studies have shown that creativity is significantly enhanced when individuals communicate with others frequently at work. ${ }^{29}$ Moreover, frequent feedback can provide useful suggestions to improve individuals' work. These suggestions also provide individuals with different perspectives and can help them produce more interesting ideas, thereby enhancing creativity. ${ }^{21}$ Since individuals in China pay more attention to self-esteem and having the respect of others, this factor should be considered in creating a coworker feedback environment. When coworkers seek feedback, they can use feedback monitoring to increase their abilities without losing face. ${ }^{30}$

Hypothesis 2: Coworker feedback monitoring is a mediator between the coworker feedback environment and creativity

\section{The moderating role of self-motives}

Employees can selectively seek feedback from coworkers. The motivation for seeking feedback is not limited to instrumental motivation but is also influenced by other motivations. ${ }^{31}$ In fact, instrumental motivation is a combination of self-improvement and self-assessment motivations, while self-protection motivation and impression management motivation are actually two aspects of selfenhancement motivation; there is limited research regarding self-verification motivation. ${ }^{31}$ While the theory of self-motivation explains feedback-seeking motivation more comprehensively and solves the past lack of classification regarding feedback-seeking motivations, it is necessary to introduce 
self-motivation for feedback seeking to analyze the moderating mechanisms. ${ }^{32}$

Feedback-seeking motivations can influence an individual's self-assessment and produce different forms of creativity. ${ }^{9}$ Most individuals verify themselves generally by creating a social environment based on their ego and subjectively distorting their reality. ${ }^{20}$ Creating a self-based social environment includes choosing the friends that one is willing to associate with, purposefully revealing one's identity, and performing self-verification by associating with others. Distorting one's reality subjectively involves selecting, recognizing, and comprehending alternatives. ${ }^{20}$ Self-improvement motivation is concerned with developing a self-concept in a better direction regardless of its accuracy. ${ }^{33}$ A coworker feedback environment offers lowcost, accurate, and credible feedback; this feedback encourages employees to enhance their individual public images by seeking feedback. Self-improvement motivation is different from the other three motivations in the sense that individuals focus on their own problems and think about whether they can truly improve their abilities. ${ }^{19}$ Therefore, self-improvement motivation belongs to the strategic aspect of self-motivation and is aimed at improving creativity; thus, self-improvement motivation may reinforce the mediating role of feedback seeking.

Hypothesis 3: When self-improvement motivation is higher, the positive relationship between coworker feedback monitoring and creativity becomes stronger.

A supportive feedback environment can reduce the cost of seeking feedback, and this situation can create opportunities for individuals to improve their self-assessment. Self-assessment motivation is concerned with the accuracy of self-cognition. Only feedback-seeking that arises from honesty and not tactics can enhance positive behavior and produce real individual growth, ${ }^{19}$ while self-verification motivation involves considering whether one can agree with the self-concept or not. However, individuals with a strong self-enhancement motivation tend to prefer positive evaluations to negative ones; these individuals particularly prefer social evaluations that are good for themselves, and they invest much energy into thinking about positive feedback. ${ }^{9}$ Individuals with a self-assessment motivation desire an external evaluation of their appearance, abilities, character, and traits; receiving this evaluation generally involves the following: (i) reducing the number of unnecessary things, (ii) focusing on what they truly look similar to in the eyes of others, and (iii) achieving small goals before recognizing their true self. ${ }^{20}$ Individuals who seek feedback by self-verification, self-enhancement and selfassessment motivations do not care about the accuracy of feedback, so these three motivations belong to the tactical aspect of self-concept enhancement and may weaken the impact of feedback-seeking behavior, but self-improvement motivation may not. ${ }^{20}$ According to the relevant feedback-related literature, individuals whose feedbackseeking motivation originates from a desire to manage their public image and the impressions of others are not interested in learning, improving their performance, or correcting potential mistakes, ${ }^{19}$ thereby likely weakening the impact of feedback-seeking behavior on creativity.

Hypothesis 4: When self-enhancement, self-verification and self-assessment motivations are lower, the positive relationship between coworker feedback monitoring and creativity becomes stronger.

The aim of this research was to analyze the association between the coworker feedback environment and creativity, to test the mediating role of feedback monitoring in this relationship and to test the moderating role of self-motivation among employees in China. Thus, we have developed our research model (Figure 1).

\section{Methods}

\section{Participants and procedure}

This study was carried out in accordance with the recommendations of the ethics committee of Liaocheng University with written informed consent from all subjects. The protocol was approved by the ethics committee of Liaocheng University (2017_7_14). All subjects have given written informed consent in accordance with the Declaration of Helsinki.

Before the survey, all participants provided written informed consent. The scope of this investigation is all the employees in 13 industrial enterprises in eastern Chinese provinces. The employees were investigated by layer cluster sampling and were stratified by group headquarters and branches. Employees provided data at three time points 3 months apart to help mitigate concerns associated with having same-time, same-source data, based on the time interval of previous studies. ${ }^{34}$ In Survey 1 (end of February 2018) we collected demographic data and measured coworker feedback environment. In Survey 2 (May 2018) employees were given the 


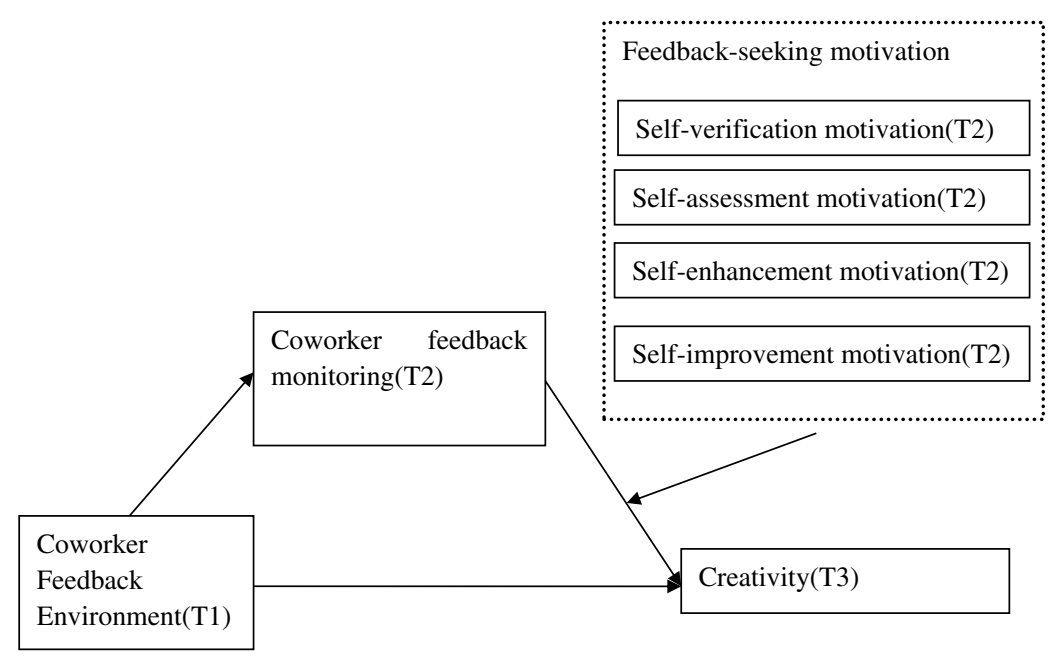

Figure I Hypothesis model.

feedback-seeking behavior questionnaire and the selfmotivation questionnaire. In Survey 3 (mid-August 2018) the employees' direct supervisors were given the creativity questionnaire. The staff submitted 264 questionnaires, of which 235 , or $74.6 \%$, of those submitted were valid.

Among the respondents in the sample, 132 (56.2\%) were men, and $103(43.8 \%)$ were women. The sample age had a centralized distribution, with 205 respondents (87.2\%) being no more than 35 years of age. The mean age is 30 and age range from $24-49$. In total, 190 respondents (80.8\%) had under 5 years of work experience, and 192 respondents $(81.7 \%)$ had completed an undergraduate education or higher.

\section{Measures}

\section{Coworkers feedback environment}

Based on our theoretical foundation of this study, we measured the coworker feedback environment by using a shortened version of the Coworker Feedback Environment Scale, which was developed by Rosen. ${ }^{6}$ This scale was widely used and tested after its launch and has been proved to have good internal consistency and reliability. The scale is a 21-item questionnaire with 7 dimensions: feedback credibility, feedback quality, feedback delivery, the accuracy of positive feedback, the accuracy of negative feedback, feedback availability, and feedback-seeking promotion; in addition, each dimension consists of 3 items. A sample item reads, "My coworkers give me useful feedback about my job performance." Each item was answered by using a 7-point Likert scale ( $1=$ strongly disagree; 7=strongly agree). In this study, Cronbach's alpha coefficient for the total scale is 0.89 . Confirmatory factor analysis was used to test all variables' construct validity, and used the standard of good fit to determine whether the variable had good structural validity: $x^{2} / d f$ is $<3$, root mean square error of approximation (RMSEA) is $<0.05$, TuckerLewis index (TLI) and comparative fit index (CFI) are over 0.90 ; thus all of the variables showed good convergent validity. The fit indices of this were $X^{2} / d f=1.63$, $R M S E A=0.04, C F I=0.91, T L I=0.92$. Hence, this is an appropriate survey to measure feedback environment.

\section{Feedback-seeking}

According to self-motives theory research, ${ }^{20}$ Callister, Kramer, and Turban's feedback-seeking scale was adopted in this questionnaire; this scale overcomes the limitations of Ashford and Ford's scale, which only distinguishes between observations and feedback seeking. ${ }^{35}$ Callister et al.'s scale not only distinguishes between feedback monitoring and feedback inquiry but also further distinguishes between the different feedback sources: superiors and coworkers. Because we were focused only on coworker feedback monitoring, 3 questions were used for measuring it and only included one dimension. A sample item reads, "From their reactions, I can tell how well I am getting along with members of my work group". All items are rated on a 7-point Likert scale (1=strongly disagree; $7=$ strongly agree). In this study, Cronbach's alpha coefficient for the scale is 0.92 . Construct validity analysis results showed that the fit indices were $X^{2} / d f=1.31$, RMSEA $=0.04, C F I=0.94, T L I=0.93$.

\section{Self-motivation}

Based on self-motives theory, we used self-motivation questionnaire compiled by Gregg et al, which includes 
four sub questionnaires corresponding to the four types of self-motivation: self-improvement, self-assessment, selfverification, and self- enhancement. ${ }^{20}$ This scale was widely used for Chinese populations for its good reliability. ${ }^{31}$ According to the Gregg et al.'s requirements, this questionnaire cannot be added to the total score of self-motivation, and each dimension needs to be individually judged to determine the size of each motivation. Therefore, each motivation questionnaire comprises 2 questions arranged in a 7-point Likert-type scale for the self-assessment of employees. Cronbach's alpha for the measure of each motivation are $0.88,0.90,0.87$ and 0.93 . Construct validity analysis results showed that the fit indices were $X^{2} / d f=1.64, R M S E A=0.05, C F I=0.91$, $T L I=0.91$.

\section{Creative performance}

Zhou and George developed the creativity scale, ${ }^{36}$ which was the most widely used and tested creativity scale. It has been proved to have good internal consistency and reliability. ${ }^{37}$ This scale has only one dimension and comprises 1 dimension which include13 topics, the average of which is about employee creativity. Utilizing the aforementioned method of subjective evaluation of employee creativity, our questionnaire asked respondents to answer each item by using a 7-point Likert scale ( $1=$ strongly disagree; 5=strongly agree). A sample scale item reads, "Seeks out new technologies, processes, techniques and/or product ideas". The Cronbach's alpha for the measure of creativity was 0.92 . Construct validity analysis results showed that the fit indices were $X^{2} / d f=1.18$, RMSEA $=0.05, C F I=0.92, T L I=0.92$.

\section{Control variables}

As in prior studies, demographic variables, such as gender, age, job tenure, and education, were controlled by statistical control variables. ${ }^{37}$

\section{Results}

\section{Data analysis}

Descriptive analyses were performed to describe the participants' demographic characteristics. Spearman's correlation coefficients were used to test the correlation among variables. Mplus 7.11 software was used to perform path analysis. According to the testing procedures for the comparison model, the coefficient multiplication method was utilized to verify the mediating effect. Finally, hierarchical regression was used to test the moderation effect of feedback-seeking motives. Differences were considered statistically significant if the $p$-value was less than 0.05 . A 95\% CI(Confidence interval), excluding 0, indicated that the mediating or moderating role is significant.

\section{Descriptive and correlation analyses}

Descriptive and correlation analyses were carried out on the variables involved in this study. The mean value, standard deviation, and correlation coefficient are shown in Table 1. These values show that the coworker feedback environment is positively related to coworker feedback monitoring $(r=0.48, \quad p<0.01)$ and creativity $(r=0.36, \quad p<0.01)$. Coworker feedback monitoring is also positively related to creativity $(r=0.25, p<0.01)$. There are significant correlations among the four types of self-motivation and creativity: self-verification $\quad(r=0.22, \quad p<0.01), \quad$ self-enhancement $(r=0.19, p<0.05)$, self-assessment $(r=0.37, p<0.01)$, and self-improvement $(r=0.28, p<0.01)$. These correlations provide a good basis for the next step of verifying the intermediary role of the different forms of coworker feedback environment and the adjustment of different feedback-seeking motives. Additionally, demographic variables, such as gender, age, and education level, are controlled.

\section{Direct effect test}

The results in Table 2 show that a coworker feedback environment has a significant, direct influence on coworker feedback monitoring $(\beta=0.53, p<0.01)$. The impact of the coworker feedback environment on creativity ( $\beta=0.60, p<0.01)$ is significant, thereby verifying hypothesis 1 . When adding coworker feedback monitoring to the model, coworker feedback monitoring significantly predicted creativity $(\beta=0.18, p<0.05)$, but the effect of the coworker feedback environment on creativity $(\beta=0.31$, $p<0.01)$ declined. The results are basically supported that coworker feedback monitoring is a mediator between the coworker feedback environment and creativity.

\section{Test of mediating effect}

The structural equation model in the Mplus 7.11 software was used for testing. First, we established the nomediating model, the partial-mediating model, and the full-mediating model through the comparison of modelfitting indexes; this comparison explores how well the model fits the actual data (Table 3). The results show that the partial-mediating model fits the data better than other nested models $(\chi 2 / d f=2.5, \quad \mathrm{RMSEA}=0.05$; $\mathrm{CFI}=0.93$; $\mathrm{GFI}=0.93)$. The CFA results suggest that the 
Table I Variable mean, standard deviation, correlation coefficient

\begin{tabular}{|c|c|c|c|c|c|c|c|c|c|c|c|}
\hline Measure & $\mathbf{I}$ & 2 & 3 & 4 & 5 & 6 & 7 & 8 & 9 & 10 & I I \\
\hline I. Coworker feedback environment (TI) & - & & & & & & & & & & \\
\hline 2. Self-enhancement motivation ( $\mathrm{TI})$ & $0.32 * *$ & - & & & & & & & & & \\
\hline 3. Self-assessment motivation ( $\mathrm{TI}$ ) & $0.31 * *$ & $0.33 * *$ & - & & & & & & & & \\
\hline 4. Self - verification motivation ( $\mathrm{TI})$ & $0.35^{* *}$ & $0.58 * *$ & $0.32 * *$ & - & & & & & & & \\
\hline 5. Self-improvement motivation ( $\mathrm{TI})$ & $0.29 * *$ & $0.43 * *$ & $0.60 * *$ & $0.52 * *$ & - & & & & & & \\
\hline 6. Coworker feedback monitoring (T2) & $0.48 * *$ & $0.5 I^{* *}$ & $0.33 * *$ & $0.28 * *$ & $0.38^{* *}$ & - & & & & & \\
\hline 7. Creativity (T3) & $0.36 * *$ & $0.22 * *$ & $0.19 *$ & $0.37^{* *}$ & $0.28 * *$ & $0.25 * *$ & - & & & & \\
\hline 8. Gender & 0.06 & 0.03 & $0.16 *$ & -0.01 & 0.05 & 0.07 & $-0.16^{*}$ & - & & & \\
\hline 9. Age & 0.02 & -0.08 & -0.05 & -0.06 & -0.01 & 0.03 & $0.11 *$ & -0.04 & - & & \\
\hline I0. Job tenure & 0.08 & 0.01 & 0.04 & 0.01 & 0.08 & 0.09 & 0.05 & $-0.19 *$ & 0.08 & - & \\
\hline II. Education & 0.11 & 0.02 & 0.02 & 0.10 & 0.01 & -0.06 & 0.09 & $-0.12^{*}$ & 0.04 & $0.36 * *$ & - \\
\hline$M$ & 4.72 & 5.01 & 5.74 & 5.11 & 5.18 & 5.23 & 4.21 & - & 2.21 & 2.49 & - \\
\hline$S D$ & 0.61 & 1.22 & 1.07 & 1.21 & 1.01 & 1.26 & 1.23 & - & 1.09 & 1.11 & - \\
\hline Potential range & $\mathrm{I}-7$ & $\mathrm{I}-7$ & $\mathrm{I}-7$ & $1-7$ & $\mathrm{I}-7$ & $1-7$ & $\mathrm{I}-7$ & $\mathrm{I}-2$ & $\mathrm{I}-5$ & $1-5$ & $1-3$ \\
\hline Actual range & $\begin{array}{l}1.0- \\
7.0\end{array}$ & $\begin{array}{l}1.0- \\
7.0\end{array}$ & $\begin{array}{l}1.0- \\
7.0\end{array}$ & $\begin{array}{l}1.0- \\
6.0\end{array}$ & $\begin{array}{l}1.0- \\
7.0\end{array}$ & $\begin{array}{l}1.0- \\
7.0\end{array}$ & $\begin{array}{l}1.0- \\
6.0\end{array}$ & $\begin{array}{l}1.0- \\
2.0\end{array}$ & $\begin{array}{l}1.0- \\
5.0\end{array}$ & $\begin{array}{l}1.0- \\
5.0\end{array}$ & $\begin{array}{l}1.0- \\
3.0\end{array}$ \\
\hline
\end{tabular}

Notes: $n=235$. ${ }^{*} p<0.05$. ${ }^{* *} p<00.01$.

Abbreviation: T, time.

Table 2 Regression results for relevant variables at different time $(\mathbf{T})$ points

\begin{tabular}{|l|l|l|l|}
\hline \multirow{2}{*}{ Independent variable } & Dependent variable & \multicolumn{3}{l|}{} \\
\cline { 2 - 4 } & Coworker feedback monitoring (T2) & Creativity (T3) & Creativity (T3) \\
\hline Intercept & $1.79^{* *}$ & $1.57^{* *}$ & $1.55^{* *}$ \\
Coworker feedback environment (TI) & $0.53^{* *}$ & $0.60^{* *}$ & $0.31^{*}$ \\
Coworker feedback monitoring (T2) & & & $0.18^{*}$ \\
$R$ & 0.17 & 0.19 & 0.02 \\
$F$ & $10.38^{* *}$ & $12.79 * *$ & $8.87^{* *}$ \\
\hline
\end{tabular}

Notes: $n=235 . * p<0.05$. $* *_{p}<00.01$. The numerical value in the table is a fully normalized path coefficient, indicating the variation of the endogenous latent variables being interpreted by exogenous latent variables.

Abbreviation: T, time.

Table 3 Comparison of structural equation

\begin{tabular}{|c|c|c|c|c|c|c|c|c|}
\hline Path model & $x^{2}$ & $d f$ & $x^{2} / d f$ & CFI & TLI & GFI & RMSEA & SRMR \\
\hline \multicolumn{9}{|c|}{ Finding Inter-mediator Variables with coworker feedback monitoring } \\
\hline Model I(Partial intermediary model) & 182.63 & 73 & 2.50 & 0.93 & 0.91 & 0.93 & 0.05 & 0.03 \\
\hline Model 2 (fully mediated model) & 221.75 & 74 & 3.00 & 0.81 & 0.79 & 0.78 & 0.09 & 0.08 \\
\hline Model 3 (Non-intermediary model) & 269.15 & 72 & 3.74 & 0.75 & 0.76 & 0.72 & 0.13 & 0.09 \\
\hline
\end{tabular}

respondents could clearly distinguish the constructs under study. Table 3 shows that the partial-mediating model fits best.

Mplus 7.11 software was used for bootstrap analysis, wherein a random sample of 5000 samples showed that the coworker feedback environment through feedback monitoring has an indirect effect on creativity at the $95 \%$ confidence interval (CI [0.02, 0.22]), which does not include 0 (Table 4). The indirect effect and coworker feedback monitoring has a mediating effect on the impact of coworker feedback environment on creativity. Therefore, hypothesis 2 is supported.

\section{Moderation effect test}

According to the type of self-motivation, feedback seeking has a moderating relationship with creativity. The analysis 
Table 4 Regression results of mediation analysis

\begin{tabular}{|l|l|l|l|l|l|}
\hline $\begin{array}{l}\text { Independent } \\
\text { variable }\end{array}$ & Mediator variable & $\begin{array}{l}\text { Dependent } \\
\text { variable }\end{array}$ & $\begin{array}{l}\text { Completely standardized } \\
\text { indirect effect }\end{array}$ & $\begin{array}{l}\text { BOOT } \\
\text { SE }\end{array}$ & \begin{tabular}{l} 
95\% CI \\
\cline { 3 - 6 }
\end{tabular} \\
\hline $\begin{array}{l}\text { Feedback environment } \\
\text { (TI) }\end{array}$ & $\begin{array}{l}\text { Co-worker feedback } \\
\text { monitoring (T2) }\end{array}$ & Creativity (T3) & 0.15 & 0.06 & 0.02 \\
\hline
\end{tabular}

Abbreviations: $\mathrm{T}$, time; $\mathrm{Cl}$, confidence interval; LL, lower limit; UL, upper limit.

results (Table 5) show that in Model 2, the coworker feedback's regression coefficient (T2) and self-assessment motivation's regression coefficient (T1) $(\beta=-0.13, p<0.01)$ have a significant interaction effect on creativity; the interaction of the other three models were not significant, indicating that the relationship between feedback monitoring and creativity is moderated by self-assessment motivation.

The relationship between the types of feedback seeking and creativity are plotted in the figures, which include the self-assessment motives of coworkers (Figure 2). It is evident that when self-assessment motives rise from a low to a high level, the relationship between coworker feedback monitoring and creativity is a straight line with a relatively steep slope that is positive $(k=0.42, p<0.01)$ and a linear change that is relatively gentle $(k=0.15, n s)$; the steep slope and gentle linear change symbolize the higher self-assessment motives. The positive relationship between coworker feedback monitoring and creativity is weaker. The Johnson-Neyman method analysis shows that self-assessment motivation has a value of less than 6.64 . The relationship between coworker feedback monitoring and creativity is significant, wherein $78.29 \%$ subjects in this study stated that coworkers' feedback has a strong and significant positive effect on creativity. This provides the basis of the next test for evidence of a conditioning role.

According to the researchers, suggested steps, the effects of interaction on the first step, the interaction between self-assessment motivation and coworker feedback monitoring $(\beta=-0.12, p<0.01)$ and the impact of this interaction on creative feedback is significant under environmental impact test conditions. The second step is evaluating the indirect effect of this interaction (Table 6); when self-assessment motivation is low, the feedback environment has an indirect effect of 0.19 on creativity through feedback monitoring (CI [0.06, 0.36]); when the selfassessment motivation is moderate, the feedback environment influences the indirect effect of creativity by 0.10 through feedback monitoring (CI $[-0.04,0.23])$. When

Table 5 Regression analysis of the adjustment effect test of self-motivation

\begin{tabular}{|c|c|c|c|c|c|}
\hline Measure & Model I & Model 2 & Model 3 & Model 4 & Model 5 \\
\hline Intercept & $3.42 * *$ & -0.50 & 3.68 & 1.96 & -2.43 \\
\hline Coworker feedback environment (TI) & & & & & $0.29 * *$ \\
\hline Coworker feedback monitoring (T2) & 0.09 & $0.17^{*}$ & -0.08 & $0.17^{*}$ & $0.16^{*}$ \\
\hline Self-enhancement motivation (TI) & 0.07 & & & & \\
\hline Self-assessment motivation (TI) & & $0.12^{*}$ & & & $0.10 *$ \\
\hline Self-verification motivation $(\mathrm{TI})$ & & & 0.07 & & \\
\hline Self-improvement motivation (TI) & & & & 0.04 & \\
\hline Co-worker feedback monitoring $(\mathrm{T} 2) \times$ & 0.02 & & & & \\
\hline self-enhancement motivation ( $\mathrm{TI}$ ) & & & & & \\
\hline Co-worker feedback monitoring (T2) $\times$ & & $-0.13^{* *}$ & & & $-0.12^{* *}$ \\
\hline self-assessment motivation (TI) & & & & & \\
\hline Co-worker feedback monitoring (T2) $\times$ & & & 0.06 & & \\
\hline self-verification motivation (TI) & & & & & \\
\hline Co-worker feedback monitoring $(\mathrm{T} 2)^{\times}$ & & & & -0.01 & \\
\hline self-improvement motivation (TI) & & & & & \\
\hline $\mathrm{R}^{2}$ & 0.12 & 0.13 & 0.21 & 0.15 & 0.20 \\
\hline$\triangle R^{2}$ & 0.01 & 0.02 & 0.01 & 0.01 & 0.07 \\
\hline $\mathrm{F}$ & 0.11 & $4.44 * *$ & 1.63 & 0.06 & $7.10 * *$ \\
\hline
\end{tabular}

Notes: $n=235$. $* p<0.05 . * * p<00.01$.

Abbreviation: T, time. 


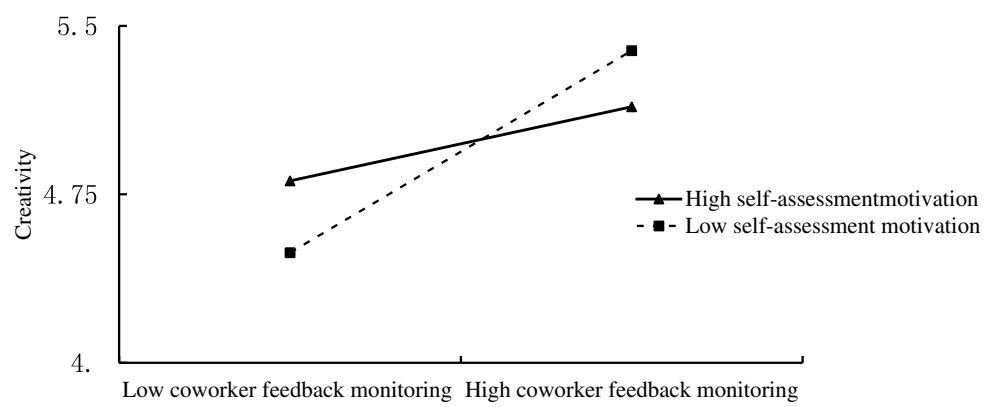

Figure 2 Simple slopes of coworker feedback environment predicting creativity at low (one SD below M) and high (one SD above M) levels of self-assessment motivation.

Table 6 Test result of condition indirect effect

\begin{tabular}{|l|l|l|l|l|l|l|l|l|l|}
\hline \multicolumn{2}{|c|}{ Moderation variable } & \multicolumn{4}{l|}{ Indirect effect of condition } & \multicolumn{3}{l|}{ Moderated mediation effect } \\
\cline { 3 - 9 } & Effect & SE & Min & Max & Index & SE & LL CI & UL CI \\
\hline Self assessment motivation & Low & 0.19 & 0.08 & 0.06 & 0.36 & -0.08 & 0.05 & -0.19 & -0.01 \\
& Mid & 0.10 & 0.07 & -0.04 & 0.23 & & & & \\
& High & 0.01 & 0.09 & -0.17 & 0.17 & & & & \\
\hline
\end{tabular}

Abbreviations: $\mathrm{Cl}$, confidence interval; LL, lower limit; UL, upper limit.

self-assessment motivation is high, the creative environment and feedback monitoring have an indirect effect of 0 0.01 on creativity through coworker feedback monitoring (CI $[-0.17,0.17])$. The results show that a creative feedback environment and coworker feedback monitoring have an indirect and significant effect on creativity only when selfassessment motivation is low. The index of moderated mediation effect is -0.08 (CI $[-0.19,-0.01)])$, and because the confidence interval does not contain 0 , the mediating effect is significant. Therefore, hypothesis 3 is partially supported, and hypothesis 4 is not supported.

In summary, this study validates the following model (Figure 3).

\section{Discussion}

Based on self-motives theory and the recommendations of previous researchers, ${ }^{9}$ the results show that the coworker feedback environment leads to creativity through coworker feedback monitoring, and when self-assessment motivation is lower, the positive relationship between coworker feedback monitoring and creativity becomes stronger.

First, we found that the coworker feedback environment positively impacts creativity. In organizational psychology and behavior research, this finding echoes the established notion that in a supportive feedback environment, employees engage in feedback seeking and receive more supportive, high-quality feedback. Coworkers convey information to employees in a way that considers the employees' feelings, making it easier for employees to accept feedback and further increase their creativity. ${ }^{28}$

Second, coworker feedback monitoring mediates the relationship between the coworker feedback environment and creativity. This impact path is similar to that described by Dahling et al, where feedback seeking has a mediator between feedback quality and performance. ${ }^{29}$ The supportive feedback environment is negatively related to the perceived cost of feedback-seeking, the alleviation of which leads to frequent feedback-seeking behavior. ${ }^{21}$ In

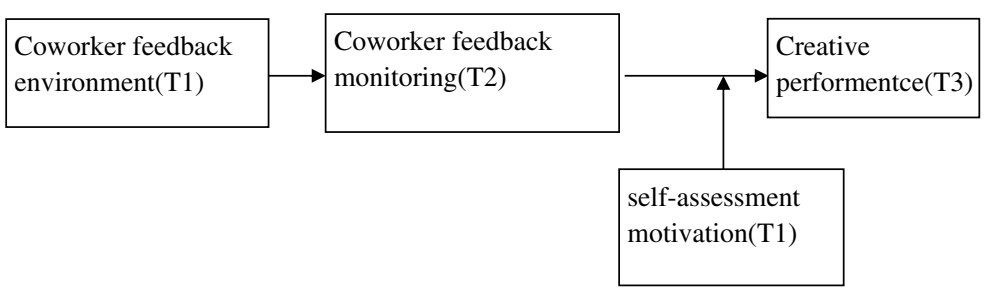

Figure 3 The validated model. 
China, a society with such a high face culture, employees are more likely to adopt feedback monitoring. The fact that individuals in China pay more attention to the face or ego should be considered in peer feedback. When individuals seek feedback, they can use feedback monitoring to increase their abilities without losing face, while creativity is significantly enhanced when individuals communicate with others frequently at work. ${ }^{38}$ Moreover, frequent feedback can provide useful suggestions for improving individuals' work. These suggestions also provide individuals with different perspectives and can help them produce more interesting ideas, thereby enhancing creativity. ${ }^{21}$

Last, feedback monitoring was positively associated with creativity only for subordinates with a low level of selfassessment motivation. Feedback monitoring that arises from honesty and not tactics can enhance positive behavior and produce real individual growth, while individuals with a self-assessment motivation can focus on how they appear in the eyes of others and reducing uncertainty. ${ }^{19}$ In agreement with much past research, when a feedback seeker asks for help with high self-assessment motivation, he/she feels great pressure to reward the feedback giver, and this pressure makes the seeker more willing to help in the future. ${ }^{12}$ Since providing feedback takes much effort and time, the more people seek to repay others for their feedback, the more positive the relationship is between feedback-seeking behavior and creativity. ${ }^{20}$ Furthermore, persons who try to use feedback to assess performance suffer from an increased affective load, and an affective load decreases creativity. ${ }^{38}$ An individuals whose feedback-seeking motivation originates from a desire to manage social impressions and their public image are not interested in learning, improving their performance, or correcting potential mistakes, ${ }^{38}$ thereby likely weakening the impact of feedback-seeking behavior on creativity.

\section{Theoretical contribution}

First, beyond single feedback intervention, this study explored the impact of a coworker feedback environment on creativity from a more comprehensive perspective. While previous studies have explored the impact of certain dimensions of feedback on creativity performance, it is difficult to reach a consistent conclusion due to the lack of comprehensiveness. As a more comprehensive concept, the feedback environment reflects the entire concept of feedback, and beyond feedback itself. The feedback environment has a positive effect on clarifying performance standards, improving work performance, and increasing employees' sense of identity, and the impact of feedback seeking on creativity is consistent with that shown in the results of previous studies. ${ }^{38}$

Second, this study differentiated between the different roles of the two feedback-seeking mechanisms in the measurement to overcome the limitation of previous research, which did not differentiate between the two feedbackseeking mechanisms or only emphasized the feedback inquiry. The conclusion of this study is similar to that of Dahling et al. ${ }^{29}$ However, Dahling et al only considered the feedback inquiry and did not determine whether the object of the feedback seeking was a supervisor or a coworker, thereby ignoring an important form of feedback seeking and obscuring the cost of feedback seeking. ${ }^{29}$ Although some studies have explored the action mechanism of seeking feedback, the focus has been only on feedback inquiry, while the role of feedback monitoring has been neglected. Perhaps for China, a society with such a high face culture, employees are more likely to adopt feedback monitoring. ${ }^{39}$ Based on the above analysis, this study accurately analyzes the path of the impact of the coworker feedback environment on creativity. Since individuals in China pay more attention to the face or ego, this factor should be considered in peer feedback. When coworkers seek feedback, they can use feedback monitoring to increase their abilities without losing face.

Third, based on self-motivation, the conditions in which different feedback-seeking behaviors play an active role are supported. Regarding the feedback-seeking motivation results, although previous research has discussed the positive correlation between inquiry feedback seeking and performance evaluation, it was found that feedback leads to reduced individual creativity; in addition, too much information may be acquired in seeking feedback, thereby causing information redundancy. ${ }^{20}$ Therefore, it is important not only to discuss how to improve creativity when solving the problem of employee demand but also to explore the positive role of feedback. Since motivation is the direct reason to promote people's activities, the main focus is on feedback-seeking motivation; further, it is thought that the occurrence and effect of feedback seeking is closely related to the seeking motivation. ${ }^{31}$

The motivation of individuals seeking feedback from coworkers through observation is derived from self-verification motivation and self-enhancement motivation. As a result, the purpose of individual information screening and analysis is different from that of the feedback sender, and the accuracy of information sought by coworkers through observational 
feedback can hardly be guaranteed. Self-assessment motivation refers to the motives for self-evaluation. A self-assessment motive is the same as the term self-concept, and selfevaluation motivation is more sensitive to the original selfconcept. $^{20}$ Individuals with self-evaluation motivation prefer accurate external feedback. If they get external evaluations of their abilities, characteristics, appearance and personality that conflict with their self-evaluations, ${ }^{20}$ they will have information redundancy. The information redundancy brought by feedback information will cause individuals to focus on processing information conflicts, leading to distraction. ${ }^{11}$ Thus, when self-assessment motivations are lower, the positive relationship between coworker feedback monitoring and creativity becomes stronger.

\section{Practical contribution}

Feedback environment is constructive when it offers concrete information that can be used. The intent is to help-that is, to maintain, correct, or improve behavior. Constructive coworker feedback environment takes into account the recipients' ability to comprehend and absorb the information and addresses elements of performance that contribute to task success and that are under the recipient's control.

Self-assessments are more likely to be accurate when they are based on easily measureable, objective criteria, not surprisingly. When self-perceptions agree with evolutions from others, people are more likely to accept the feedback. However, they may not learn from the feedback and change their behavior as a result. Favorable ratings suggest no change is needed. Unfavorable ratings may merely affirm the receivers' low self-perception. So the receiver may not take action to change behavior even though such action is called for.

People who underestimate their performance in the eyes of others may adjust their self-perceptions upward but not change their behavior. People who over-estimate their performance may have trouble facing facts and my look for ways to deny or rationalize the negative feedback. Specific feedback is likely to increase the likelihood that the feedback recipient will take action to change his or her behavior and improve his or her creativity However, feedback is likely to be infrequent and subjective, and therefore easily ignored as inaccurate and not to be trusted.

\section{Limitations and future research}

This study has several limitations, which indicate the direction for future research. First, this study focuses on the impact of four kinds of self-motivation. Feedback researchers have identified various types of motivations that can affect feedback-seeking behavior, but empirical research on the interaction between multiple motivations is still limited. Future studies should focus on how to elicit feedback-seeking motivation and avoid other theoretical motivations that prevent feedback seeking. Furthermore, future research must determine how to motivate and develop feedbackseeking and feedback-providing behavior and determine the impact of this behavior on work practices.

Second, the dynamic emotional mechanism of the impact of the feedback environment on creativity needs to be further explored. Previous studies regarding the impact of a feedback environment often discuss the motivation mechanism; however, a more direct consequence of a feedback environment is a strong emotional response from employees, which affects creativity. ${ }^{40}$ Therefore, emotional motivation may be the link between situational factors and behavior. The interpersonal interactions involved in a feedback environment can cause an individual's emotions to change quickly during the creativity process. ${ }^{40}$ Since the emotional changes caused by individuals' focus and mindset changes affect feedbackseeking behavior, two studies were analyzed based on the same framework, and future research must study this dynamic mechanism in further detail.

Third, although this study incorporated the cognitive processing of feedback into information into the motivation process, this study does not verify whether this motivation process was successful. It is very important to determine whether cognitive processes play a positive or a negative role in the various feedback-seeking methods. Studies have shown that when employees cannot judge a situation, the cost of a proactive personality is inversely proportional to job satisfaction. Consequently, they will face more interpersonal conflicts, and the matching of personal organizations can ensure positive proactive behavior, while antisocial behavior has a destructive effect on individuals, the society, and organizations. Researchers have also found that when individuals are under constant pressure to demonstrate proactive selfhelp behaviors and experience work overload and work-life balance conflicts, proactive behaviors tend to decline over time. ${ }^{41}$ Therefore, future research should examine not only the positive role of feedback seeking but also its drawbacks.

\section{Conclusion}

It was suggested that a coworker feedback environment could improve employee creativity by promoting coworker feedback monitoring; creativity could be improved especially among employees who have lower self-assessment motivation. 


\section{Acknowledgments}

This research was supported by the National Natural Science Foundation of China (71801120), the Ministry of Education of Humanities and Social Science Research Youth Fund Project of China (18YJC630038), National Innovation and Entrepreneurship Training Program (201910447073) and the China Scholarship Council (201908370108).

\section{Author contributions}

All authors contributed to data analysis, drafting or revising the article, gave final approval of the version to be published, and agree to be accountable for all aspects of the work.

\section{Disclosure}

The authors report no conflicts of interest in this work.

\section{References}

1. Zhou J. When the presence of creative coworkers is related to creativity: role of supervisor close monitoring, developmental feedback, and creative personality. J Appl Psychol. 2003;88(3):413-422. doi:10.1037/0021-9010.88.3.413

2. Bledow R, Rosing K, Frese M. A dynamic perspective on affect and creativity. Acad Manage J. 2013;56(2):432-450. doi:10.5465/ amj.2010.0894

3. Mannucci PV, Yong K. The differential impact of knowledge depth and knowledge breadth on creativity over individual careers. Acad Manage J. 2018;61(5):1741-1763. doi:10.5465/amj.2016.0529

4. Kluger AN, DeNisi A. The effects of feedback interventions on performance: a historical review, a meta-analysis, and a preliminary feedback intervention theory. Psychol Bull. 1996;119(2):254-284. doi:10.1037/0033-2909.119.2.254

5. Steelman LA, Levy PE, Snell AF. The feedback environment scale: construct definition, measurement, and validation. Educ Psychol Meas. 2004;64(1):165-184. doi:10.1177/0013164403258440

6. Rosen CC, Levy PE, Hall RJ. Placing perceptions of politics in the context of the feedback environment, employee attitudes, and job performance. J Appl Psychol. 2006;91(1):211-220. doi:10.1037/00219010.91.1.211

7. Zhang J, Gong Z, Zhang S, Zhao Y. Impact of the supervisor feedback environment on creative performance: a moderated mediation model. Front Psychol. 2017;8(1):256. doi:10.3389/fpsyg.2017.00256

8. Dong Y, Bartol KM, Zhang Z, Li C. Enhancing employee creativity via individual skill development and team knowledge sharing: influences of dual-focused transformational leadership. J Organ Behav. 2017;38(3):439-458. doi:10.1002/job.2134

9. Dahling JJ, O'Malley AL. Supportive feedback environments can mend broken performance management systems. Indus Organ Psycho. 2011;4(2):201-203. doi:10.1111/j.1754-9434.2011.01327.x

10. Andiola LM. Performance feedback in the audit environment: a review and synthesis of research on the behavioral effects. $J$ Account Lit. 2014;33(1-2):1-36. doi:10.1016/j.acclit.2014.07.001

11. Gong Z, Zhang N. Using a feedback environment to improve creative performance: a dynamic affect perspective. Front Psychol. 2017;8:1398. doi:10.3389/fpsyg.2017.01398

12. Sedikides C, Strube MJ. Self-evaluation: to thine own self be good, to thine own self be sure, to thine own self be true, and to thine own self be better. Adv Exp Soc Psychol. 1997;29(08):209-269. doi:10.1016/ S0065-2601(08)60018-0
13. Evraire LE, Ludmer JA, Dozois DJA. The influence of priming attachment styles on excessive reassurance seeking and negative feedback seeking in depression. J Soc Clin Psychol. 2014;33 (4):295-318. doi:10.1521/jscp.2014.33.4.295

14. Whitaker BG, Dahling JJ, Levy P. Explicating the links between the feedback environment, feedback seeking, and job performance. $J$ Manage. 2007;33(4):570-591. doi:10.1177/0149206306297581

15. Niemann J, Wisse B, Rus D, Van Yperen NW, Kai S. When uncertainty counteracts feedback seeking: the effects of interpersonal uncertainty and power on direct feedback seeking. Euro J Work Organ Psycho. 2015;24(2):211-224. doi:10.1080/1359432X.2013.871260

16. London M. The Power of Feedback: Giving, Seeking, and Using Feedback for Performance Improvement. New York: Routledge; 2014. doi:10.4324/9781315813875

17. Anseel F, Beatty AS, Shen W, Lievens F, Sackett PR. How are we doing after 30 years? A meta-analytic review of the antecedents and outcomes of feedback-seeking behavior. J Manage. 2015;41(1):318-348.

18. Wu C, Parker SK, de Jong JP. Feedback seeking from peers: a positive strategy for insecurely attached team-workers. Hum Relat. 2013;67(4):441-464. doi:10.1177/0018726713496124

19. Gregg AP, Sedikides C. Narcissistic fragility: rethinking its links to explicit and implicit self-esteem. Self Identity. 2010;9:142-161. doi:10.1080/15298860902815451

20. Gregg AP, Hepper EG, Sedikides C. Quantifying self-motives: functional links between dispositional desires. Eur J Soc Psychol. 2011;41 (7):840-852. doi:10.1002/ejsp.827

21. van der Rijt J, van den Bossche P, SR Segers M. Understanding informal feedback seeking in the workplace: the impact of the position in the organizational hierarchy. Euro J Train Develop. 2013;37 (1):72-85. doi:10.1108/03090591311293293

22. Dahling JJ, Gabriel AS, MacGowan R. Understanding typologies of feedback environment perceptions: a latent profile investigation. $J$ Vocat Behav. 2017;101:133-148. doi:10.1016/j.jvb.2017.05.007

23. Steelman LA, Wolfeld L. The manager as coach: the role of feedback orientation. J Bus Psychol. 2018;33(1):41-53. doi:10.1007/s10869-0169473-6

24. Whitaker BG, Dahling JJ, Levy P. The development of a feedback environment and role clarity model of job performance. J Manage. 2016;33(4):570-591. doi:10.1177/0149206306297581

25. Peng JC, Chiu SF. An integrative model linking feedback environment and organizational citizenship behavior. J Soc Psychol. 2010;150(6):582-607. doi:10.1080/00224540903365455

26. Tuckey M, Brewer N, Williamson P. The influence of motives and goal orientation on feedback seeking. J Occup Organ Psychol. 2011;75(2):195-216. doi:10.1348/09631790260098677

27. Norris-Watts C, Levy PE. The mediating role of affective commitment in the relation of the feedback environment to work outcomes. $J$ Vocat Behav. 2004;65(3):351-365. doi:10.1016/j.jvb.2003.08.003

28. Janssen S, Tahitu J, van Vuuren M, de Jong MDT. Coworkers' perspectives on mentoring relationships. Group Organ Manage. 2016;43(2):245-272. doi:10.1177/1059601116669641

29. Whitaker BG, Levy P. Linking feedback quality and goal orientation to feedback seeking and job performance. Hum Perform. 2012;25 (2):159-178. doi:10.1080/08959285.2012.658927

30. Winning AM, Merandi JM, Lewe D, et al. The emotional impact of errors or adverse events on healthcare providers in the NICU: the protective role of coworker support. J Adv Nurs. 2018;74(1):172180. doi:10.1111/jan.13403

31. Anseel F, Lievens F, Levy PE. A self-motives perspective on feedback seeking behavior: linking organizational behavior and social psychology research. Int $J$ Manag Rev. 2007;9(3):211-236. doi:10.1111/j.1468-2370.2007.00210.x

32. van der Rijt J, Van den Bossche P, van de Wiel MWJ, Segers MSR, Gijselaers WH. The role of individual and organizational characteristics in feedback seeking behaviour in the initial career stage. Hum Resour Develop Inter. 2012;15(3):283-301. doi:10.1080/13678868.2012.689216 
33. Neiss MB, Sedikides C, Shahinfar A, Kupersmidt JB. Self-evaluation in a naturalistic context: the case of juvenile offenders. Brit J Soc Psychol. 2011;45(3):499-518. doi:10.1348/014466605X64486

34. Gabriel AS, Frantz NB, Levy PE, Hilliard AW. The supervisor feedback environment is empowering, but not all the time: feedback orientation as a critical moderator. J Occup Organ Psychol. 2014;87 (3):487-506. doi:10.1111/joop.12060

35. Callister RR, Turban DB. Feedback seeking following career transitions. Acad Manage J. 1999;42(4):429-438. doi:10.2307/257013

36. Zhou J, George JM. When job dissatisfaction leads to creativity: encouraging the expression of voice. Acad Manage J. 2001;44 (4):682-696. doi: $10.2307 / 3069410$

37. Hoever IJ, Zhou J, van Knippenberg D. Different strokes for different teams: the contingent effects of positive and negative feedback on the creativity of informationally homogeneous and diverse teams. Acad Manage J. 2018;61(6):2159-2181. doi:10.5465/amj.2016.0642
38. Harrison SH, Dossinger K. Pliable guidance: a multilevel model of curiosity, feedback seeking, and feedback giving in creative work. Acad Manage J. 2017;60(6):2051-2072. doi:10.5465/amj.20 15.0247

39. Gielen M, De Wever B. Scripting the role of assessor and assessee in peer assessment in a wiki environment: impact on peer feedback quality and product improvement. Comput Educ. 2015;88:370-386. doi:10.1016/j.compedu.2015.07.012

40. Choi E, Johnson DA, Moon K, Oah S. Effects of positive and negative feedback sequence on work performance and emotional responses. $J$ Organ Behav Manage. 2018;38(2-3):97-115. doi:10.1080/01608061. 2017.1423151

41. Bolino MC, Turnley WH. The personal costs of citizenship behavior: the relationship between individual initiative and role overload, job stress, and work-family conflict. J Appl Psychol. 2005;90(90):740748. doi:10.1037/0021-9010.90.4.740
Psychology Research and Behavior Management

\section{Publish your work in this journal}

Psychology Research and Behavior Management is an international, peer-reviewed, open access journal focusing on the science of psychology and its application in behavior management to develop improved outcomes in the clinical, educational, sports and business arenas. Specific topics covered in the journal include: Neuroscience, memory and decision making; Behavior modification and management; Clinical

\section{Dovepress}

applications; Business and sports performance management; Social and developmental studies; Animal studies. The manuscript management system is completely online and includes a very quick and fair peer-review system, which is all easy to use. Visit http://www. dovepress.com/testimonials.php to read real quotes from published authors. 